\title{
Confusion about infusion: Rational volume guidelines for intravenous lipid emulsion during treatment of oral overdoses
}

Authors: Michael R Fettiplace ${ }^{1,2}$, Belinda S $\mathrm{Akpa}^{3}$, Israel Rubinstein ${ }^{2,4}$, Guy Weinberg ${ }^{1,2}$,

\section{Affiliations:}

1: Department of Anesthesiology, University of Illinois College of Medicine, 1740 West Taylor Street, Suite 3200W, MC515, Chicago, IL 60612

2: Research \& Development Service, Jesse Brown VeteransAffairs Medical Center, 820 S. DamenAvenue, 60612

3:Department of Chemical Engineering; University of Illinois at Chicago, $810 \mathrm{~S}$.

Clinton Street, Chicago, IL 60607

4: Section of Pulmonary, Critical Care, Sleep and Allergy Medicine, Department of Medicine, University of Illinois College of Medicine, 840 South Wood Street (MC 719), Room 920-N CSB, Chicago, IL, 60612

Corresponding Authors:

Michael Fettiplace, MS

Department of Anesthesiology M/C515

University of Illinois Hospital \& Health Sciences System

$1740 \mathrm{~W}$. Taylor

Chicago, IL 60612

Fax: 312-569-8114

Email:mfetti3@uic.edu

Acknowledgements:Mr. Fettiplace is supported by the Department of Anesthesiology at the University of Illinois College of Medicine (Chicago, IL, USA) \&by an American Heart Association (Dallas, TX, USA) Predoctoral Fellowship 13PRE16810063. Dr. Akpa is supported by National Science Foundation (Arlington, VA, USA) Grant 1228035.Dr. Weinberg \& Dr. Rubinstein are supported by United States Veterans Administration (Washington DC, USA) Merit Review \&NIH CounterACT grant 1U01NS083457-01. 
Following the initial report of treatment of buproprion and lamotrigine overdose by intravenous lipid emulsion (ILE) (1), additional case reports have asserted the usefulness of ILE for enteral poisonings $(2,3)$. Based on these and other reports, the American College of Medical Toxicology (ACMT) offered interim guidelines on lipid resuscitation therapy (4);they recommended a $1.5 \mathrm{~mL} / \mathrm{kg}$ bolus followed by an infusion of $0.25 \mathrm{~mL} / \mathrm{kg} / \mathrm{min}$ of ILE if toxicity persists. The ACMT recommendation was based on guidelines for treatment of local anesthetic toxicity $(5,6)$ where absorption is quick and toxicity short-lived.In contrast to local-anesthetic toxicity, prolonged absorption during enteral overdose can result in extendedtoxicity with a need for continuing medical support including a protracted infusion of ILE. Guidelines for ILEin local-anesthetic toxicity set an upper limit of $10-12 \mathrm{~mL} / \mathrm{kg}$ over the first half an hour but due to the aforementioned nature of oral overdoses, the ACMT did not provide a limit on total lipid infusion volume or duration of infusion. In the absence of limits, an increasing number of cases havereported the use oflarge volumes of ILE to treat oral overdose. However, until definitive studies can be conducted, there is a need for rational volume limits to prevent undisciplined use of ILE.

With the increased adoption of ILE, several case reports have identified the potential usefulness of prolonged lipid infusions for enteral toxicity (7-10). In the largest aggregation of cases, Cave et al reported that ILE improved Glasgow-coma-scale ratings and increased systolic blood pressure during treatment of non-local anesthetic overdosein 38 patients (8). The average dose of ILE used in these cases was $531 \pm$ $22 \mathrm{~mL}$, which is within ranges recommended by professional societies $(5,6)$. With these doses, there were no significant adverse effects except interference with laboratory 
tests due to lipemia and an asymptomatic elevation of serum amylase in one patient. More recently Cevik et al reported ten patients who received extended ILE infusions of very large volumes for central nervous system depression or cardiovascular instability due to enteral drug overdose(9). Eight of the patients received $3100-4300 \mathrm{~mL}$ of ILE over a two-hour period and twonon-life threatening complications were reported as associated with lipid infusion (hyperamylasia and transient pulmonary infiltrates two days after end of ILE). In another case involving a largelLE volume, Meaney and colleagues treated a patient with $2100 \mathrm{~mL}$ ILE over 4 hours followed by improvement of the patient's amlodipine toxicity(10). The improved hemodynamic stability in these cases was associated with continuing infusion, and the physicians' decision to administer such high total volumes of lipid (> 1L) suggests that ILEmay have contributed to patients'recovery.

In contrast, a number of recent publications have identified adverse events associated with ILE (albeit with many confounders), particularly the use of very large volumes of lipidemulsion (11-14). Bucklin et al reported a patient who received $42 \mathrm{~mL} / \mathrm{kg}$ of ILE and subsequently had lipemia and hyperamylasia(11) but recovered and was discharged. Martin et al reported a patient who received 3220 mLover 4 hours $(0.2 \mathrm{~mL} / \mathrm{kg} / \mathrm{min})$ and developed acute respiratory distress syndrome(12), possibly related to ILE and involved additional hospitalization before recovery. In another report by Shenoy and colleagues, an $11 \mathrm{~kg}$ pediatric patient received $170 \mathrm{~mL}$ of ILE over one hour producing a normalized total dose of $30 \mathrm{~mL} / \mathrm{kg}$ (13)and experiencedventilation/perfusion mismatching. One important caveat in this and similar cases is that the patient also received very high doses of epinephrine, a treatment that is known to cause pulmonary 
complications (15). In the most worrisome report, Rodríguez et al reported a patient who was given a total of $6200 \mathrm{~mL}(\sim 79 \mathrm{~mL} / \mathrm{kg})$ of $20 \%$ Intralipid® over 5 -hours, before discontinuation due to clogging of the continuous renal replacement therapy (RRT) filter(14). This patient subsequently died. Other recent reports have also cautioned about possible risks of lipid emulsion therapy $(7,16,17)$ - risks that are documented for lipid emulsions in the absence of other drug toxicity (18). Virtually all these cases involved treatment of enteral overdose and in the majority of cases, the lipid volumes far exceeded the FDA recommended dosing limits of $12.5 \mathrm{~mL} / \mathrm{kg}$ over 24 hoursin adults and $15 \mathrm{~mL} / \mathrm{kg}$ in pediatric patients $(19,20)$. It should be noted that the FDA limits were established for nutritional support rather than acute drug toxicity.

Given this information, we believe that the continued use of ILE for enteral intoxications necessitates identifying safe upper dosinglimits and rationally-based infusion regimes that are not merely an extension of established treatment guidelines for local anesthetic toxicity. The case report of lipemic interference with RRT especially gives one pause. That patient received $79 \mathrm{~mL} / \mathrm{kg}$ of ILE over six hours(14), an extremely high dose by any measure, particularly considering that the LD50 for rats given $20 \%$ Intralipid® over 30 minutes is $67.7 \pm 10.7 \mathrm{~mL} / \mathrm{kg}$ (21). Taking into accountallometric scaling and differences in metabolism, we are concerned that this dose of lipid may not have improved the patient's condition. Notably, Cave et al's retrospective analysis (7) indicated that patients often appeared to derive benefitfrom much smaller doses of ILE $(\sim 7 \mathrm{~mL} / \mathrm{kg})$ suggesting a favorable therapeutic index. Indeed, the case series from Cevik and colleagues(9) supports a considerable safety margin for ILE since patients received upwards of $30 \mathrm{~mL} / \mathrm{kg}$ over 2 hours and the adverse events were non-life-threatening. 
Nevertheless, infusing $3-4 \mathrm{~L}$ of $20 \%$ lipid emulsion over 2 hours is sailing uncharted waters.

Presumably the goal of an extended infusion is to maintain alipemic plasma without inducing fat overload. The need for lipemic plasma is based on the accumulating evidence that ILE functions both as a scavenging agent to accelerateredistribution of the offending drug (22-26); and as a direct inotropetoimprovecardiovascular performance $(22,27-29)$. The latter mechanism is consistent with the observation that small volume infusions $(40 \mathrm{~mL} / \mathrm{h})$ of $20 \%$ Intralipid® elevate blood pressurein healthy patients while only moderately raising triglyceride concentrations(30-32). Based on these assumptions, we used aphysiologically-based pharmacokinetic-pharmacodynamicmodel that has been repeatedly back-tested against physiological data $(22,28,33)$ to estimate a rational infusion regime needed to maintain a modestly lipemic plasma. We adjusted the model for a $72 \mathrm{~kg}$ man and $20 \%$ lipid emulsion, and then tested four scenarios.

(A) A concentration-independent rate of lipid metabolism and atriglyceride half-life of $\sim 10$ minutes (34). A1.5 ml/kg bolus followed by 0.25 $\mathrm{ml} / \mathrm{kg} / \mathrm{min}$ infusion for 60 minutes caused a peak lipid volume fraction during the infusion which dropped to near zero within 30 minutes after discontinuing the infusion (Figure 1). Increasing infusion duration cannot sustain lipemic plasma because lipid is metabolized too quickly. This disagrees with case reports that identifylipemic plasma with 
continued infusion since theseindicate that processing of ILE does saturate.

(B) Saturation of lipid metabolism as per the findings of Robin et al (34). A Michaelis-Menten rate expression was employed with a saturation constant of $1222 \mu \mathrm{mol} / \mathrm{L}$, corresponding to a triglyceride volume fraction of $0.1 \%$ and a maximum processing rate of $110 \mu \mathrm{mol} / \mathrm{L} / \mathrm{min}$. In the case of a $1.5 \mathrm{~mL} / \mathrm{kg}$ bolus followed by a $0.25 \mathrm{ml} / \mathrm{kg} / \mathrm{min}$ infusion for 60 minutes, lipid accumulatesin the plasma throughout infusion because the rate of deliveryexceeds the rate of metabolic clearance. At the end of infusion, lipid concentration decays with a half-life of $\sim 3$ hours.

(C) The extended ILE infusion scenario (9)with a $1.5 \mathrm{~mL} / \mathrm{kg}$ bolus and a $0.25 \mathrm{ml} / \mathrm{kg} / \mathrm{min}$ infusion for 300 minutes. In this scenario, lipid concentration risescontinuously over the infusion period to levels that cause concern.

(D) To produce a plasma triglyceride concentration of $\sim 1 \%$, a loading dose of $1.5 \mathrm{ml} / \mathrm{kg}$ was delivered over 1 minute with an additional 0.25 $\mathrm{ml} / \mathrm{kg} / \mathrm{min}$ over 3 minutes, and then maintained with $0.025 \mathrm{ml} / \mathrm{kg} / \mathrm{min}$.

We recommend against the dosing method used in scenario $C$ because the total delivered dose is far above the FDA recommended levels, and within range of the LD50 in animal models. Even the dosing in case B could elevate plasma triglycerides more than we believe is required based on the proposed mechanisms of ILE. Basic science 
studies demonstrate that ILE concentrations as low as $0.25 \%$ can produce positive inotropic effects $(27,35)$ and clinical cases report that infusions as low as 0.008 $\mathrm{mL} / \mathrm{kg} / \mathrm{min}$ are associated with profound effects on physiological parameters (30-32). Therefore, the $1 \%$ plasma triglyceride concentration generated by the dosingscheme inscenario $D$ should be sufficient to provide both scavenging and cardiotonicbenefits $(22,27)$. The effectiveness of such a low dose is reflected in two case reports thatnotedfavorable outcomes of enteral overdoses using infusion rates of $0.02 \mathrm{~mL} / \mathrm{kg} / \mathrm{min}$ or below. Agarwala et al used an infusion rate of $100 \mathrm{~mL} / \mathrm{hour}$ $(\sim 0.02 \mathrm{~mL} / \mathrm{kg} / \mathrm{min})$ for 24 hours to accelerate detoxificationof tricyclic overdose(36). Bologa et al used an even lower rate $(0.008 \mathrm{~mL} / \mathrm{kg} / \mathrm{min})$ for 12 hours to treat a diltiazem overdose, whichwas associated with a "favorable evolution" and improvement in blood pressure(37). Bothpatients had lipemic serum but survived to discharge, supporting the possible efficacy of these low infusion rates.

Based on case reports and the putative mechanisms of lipid resuscitation, we conclude that a low-rate infusion of ILEshould provide clinical benefit during enteral intoxication (as an adjuvant to standard protocols). Needless to say, comprehensive studies are indicated to determine the appropriate dosing for prolonged enteral intoxication but since oral overdoses remain a major public health issue, a rational guideline is needed currently. With a suspected enteral overdose, we advise the traditional bolus of $1.5 \mathrm{~mL} / \mathrm{kg}$ and an additional $0.25 \mathrm{~mL} / \mathrm{kg} / \mathrm{min}$ over 3-minutes (total initial load of $2.25 \mathrm{~mL}$ or $\sim 150 \mathrm{~mL}$ ) followed by aninfusion of $0.025 \mathrm{~mL} / \mathrm{kg} / \mathrm{min}$, which can be maintained for up to 6.5 hours. This targets a total dose below the 24 -hour infusion limit of $12.5 \mathrm{~mL} / \mathrm{kg}$ set by the FDA. Higher infusion rates or volumes of ILE might be 
appropriate but by starting with this lower infusion rate, clinicians would have the flexibility to infuse an additional bolus for cardiovascular instability or increase the rate if blood pressure sags. Note that by increasing the rate, one will arrive at the $12.5 \mathrm{~mL} / \mathrm{kg}$ volume limit faster. Higher infusion rates may be avoided by combining ILE with alternative methods(i.e. high-dose-insulin, methylene blue) $(38,39)$ and thesemethods can be emphasized once lipid volume limits are reached. Importantly, serumtriglyceride concentrations should be monitored, targeting approximately $1 \%(1000 \mathrm{mg} / \mathrm{dL})$ while remaining mindful of the 24 -hour limit. These recommendations are for cardiac instability following oral overdose (e.g. tricyclic antidepressants, calcium channel blockers, etc...) but this infusion paradigm could be beneficial during suspected overdose before cardiovascular collapse ensues, especially given that ILE scavenges drugs most effectively at high drug concentrations $(22,40)$. Clinicians should be aware that Intralipid® can clog RRT filters $(14,41,42)$, although RRTand ILE have been used together without complications $(36,43,44)$. Lastly, we encourage healthcare providers to publish their findings with extended infusions for peer-review and encourage researchers to investigate prolonged infusions in animal models of enteral overdose. 


\section{References}

1. Sirianni AJ, Osterhoudt KC, Calello DP, Muller AA, Waterhouse MR, Goodkin MB, et al. Use of Lipid Emulsion in the Resuscitation of a Patient With Prolonged Cardiovascular Collapse After Overdose of Bupropion and Lamotrigine. Ann Emerg Med. Elsevier; 2008;51(4):412-5.

2. Cave G, Harvey M. Intravenous Lipid Emulsion as Antidote: Beyond Local Anesthetic Toxicity: A Systematic Review. Acad Emerg Med. 2009;16(9):815-24.

3. Weinberg G. Lipid Emulsion Infusion Resuscitation for Local Anesthetic and Other Drug Overdose. Anesthesiology. 2012;117(1):180-7.

4. ACMT position statement: interim guidance for the use of lipid resuscitation therapy. J Med Toxicol. 2011 Mar;7(1):81-2.

5. G C, Harrop-Griffiths W, Harbey M, Meek T, Picard J, Short T, et al. AAGBI Safety Guideline: Management of Severse Local Anaesthetic Toxicity. The Associaton of Anaesthetists of. 2010.

6. Neal JM, Bernards CM, Butterworth JF, Di Gregorio G, Drasner K, Hejtmanek MR, et al. ASRA practice advisory on local anesthetic systemic toxicity. Reg Anesth Pain Med. 2010;35(2):152-61.

7. Cave G, Harvey M, Willers J, Uncles D, Meek T, Picard J, et al. LIPAEMIC Report: Results of Clinical Use of Intravenous Lipid Emulsion in Drug Toxicity Reported to an Online Lipid Registry. J Med Toxicol. 2014 Jan 11;10(2):133-42.

8. Mirtallo JM, Dasta JF, Kleinschmidt KC, Varon J. State of the art review: Intravenous fat emulsions: Current applications, safety profile, and clinical implications. Ann Pharmacother. 2010 Apr;44(4):688-700.

9. Eren Cevik S, Tasyurek T, Guneysel O. Intralipid emulsion treatment as an antidote in lipophilic drug intoxications: a case series. Am J Emerg Med. Elsevier Inc.; 2014 May 21;10:1-6.

10. Meaney CJ, Sareh H, Hayes BD, Gonzales JP. Intravenous lipid emulsion in the management of amlodipine overdose. Hosp Pharm. 2013 Nov;48(10):848-54.

11. Bucklin MH, Gorodetsky RM, Wiegand TJ. Prolonged lipemia and pancreatitis due to extended infusion of lipid emulsion in bupropion overdose. Clin Toxicol (Phila). 2013 Nov;51(9):896-8.

12. Martin C, Gonzalez H, Ruiz S, Ribes D, Franchitto N, Minville V. Acute respiratory distress syndrome following verapamil overdose treated with intravenous lipid 
emulsion: a rare life-threatening complication. Ann Fr Anesth Reanim. Elsevier Masson SAS; 2014 Jun;33(6):e101-2.

13. Shenoy U, Paul J, Antony D. Lipid resuscitation in pediatric patients - need for caution? Paediatr Anaesth. 2014 Mar;24(3):332-4.

14. Rodríguez B, Wilhelm A, Kokko KE. Lipid Emulsion Use Precluding Renal Replacement Therapy. J Emerg Med. 2014 Sep 27;1-3.

15. Krishnamoorthy V, Hiller D, Ripper R, Lin B, Vogel S, Feinstein D, et al. Epinephrine Induces Rapid Deterioration in Pulmonary Oxygen Exchange in Intact, Anesthetized Rats: A Flow and Pulmonary Capillary Pressure-dependent Phenomenon. Anesthesiology. 2012;117(4):745-54.

16. Levine M, Brooks DE, Franken A, Graham R. Delayed-onset seizure and cardiac arrest after amitriptyline overdose, treated with intravenous lipid emulsion therapy. Pediatrics. 2012 Aug;130(2):e432-8.

17. Levine M, Skolnik A, Ruha A, Bosak A, Menke N, Pizon A. Complications following antidotal use of intravenous lipid emulsion therapy. J Med Toxicol. 2014;10(1):10-4.

18. Nanji A, Poon R, Hinberg I. Lipaemic interference: effects of lipaemic serum and intralipid. J Clin Pathol. 1988;41(9):1026-7.

19. Infusion C. ClinOleic Infusion, emulsion. 2014;(September):1-15.

20. Intralipid® 20 \%: A 20\% I.V. Fat Emulsion In Excel® Container. 2004.

21. Hiller DB, Di Gregorio G, Kelly K, Ripper R, Edelman L, Boumendjel R, et al. Safety of High Volume Lipid Emulsion Infusion: A First Approximatin of LD50 in Rats. Reg Anesth Pain Med. 2010 Mar;35(2):140-4.

22. Fettiplace MR, Lis K, Ripper R, Kowal K, Pichurko A, Vitello D, et al. Multi-modal contributions to detoxification of acute pharmacotoxicity by a triglyceride microemulsion. J Control Release. Elsevier B.V.; 2015 Dec 4;198:62-70.

23. Heinonen J a, Litonius E, Salmi T, Haasio J, Tarkkila P, Backman JT, et al. Intravenous Lipid Emulsion given to Volunteers does not affect Symptoms of Lidocaine Brain Toxicity. Basic Clin Pharmacol Toxicol. 2014 Sep 10;[Epub ahead of print].

24. Shi K, Xia Y, Wang Q, Wu Y, Dong X, Chen C, et al. The effect of lipid emulsion on pharmacokinetics and tissue distribution of bupivacaine in rats. Anesth Analg. 2013 Apr;116(4):804-9. 
25. Heinonen J a, Litonius E, Backman JT, Neuvonen PJ, Rosenberg PH. Intravenous Lipid Emulsion Entraps Amitriptyline into Plasma and Can Lower its Brain Concentration - An Experimental Intoxication Study in Pigs. Basic Clin Pharmacol Toxicol. 2013 May 3;113(3):193-200.

26. Litonius E, Tarkkila P, Neuvonen PJ, Rosenberg PH. Effect of intravenous lipid emulsion on bupivacaine plasma concentration in humans. Anaesthesia. 2012 Jun;67(6):600-5.

27. Fettiplace MR, Ripper R, Lis K, Lin B, Lang J, Zider B, et al. Rapid Cardiotonic Effects of Lipid Emulsion Infusion. Crit Care Med. 2013;41(8):e156-62.

28. Fettiplace MR, Akpa B, Ripper R, Zider B, Lang J, Rubinstein I, et al. Resuscitation with Lipid Emulsion: Dose-dependent Recovery from Cardiac Pharmacotoxicity Requires a Cardiotonic Effect. Anesthesiology. 2014;120(4):915-25.

29. Stehr SN, Ziegeler JC, Pexa A, Oertel R, Deussen A, Koch T, et al. The effects of lipid infusion on myocardial function and bioenergetics in I-bupivacaine toxicity in the isolated rat heart. Anesth Analg. 2007 Jan;104(1):186-92.

30. Gosmanov AR, Smiley DD, Peng L, Siquiera J, Robalino G, Newton C, et al. Vascular effects of intravenous intralipid and dextrose infusions in obese subjects. Metabolism. Elsevier Inc.; 2012 Oct;61(10):1370-6.

31. Umpierrez GE, Smiley D, Robalino G, Peng L, Kitabchi AE, Khan B, et al. Intravenous intralipid-induced blood pressure elevation and endothelial dysfunction in obese African-Americans with type 2 diabetes. J Clin Endocr Metab. 2009 Feb;94(2):609-14.

32. Siqueira J, Smiley D, Newton C, Le N-A, Gosmanov AR, Spiegelman R, et al. Substitution of standard soybean oil with olive oil-based lipid emulsion in parenteral nutrition: comparison of vascular, metabolic, and inflammatory effects. J Clin Endocr Metab. 2011 Oct;96(10):3207-16.

33. Kuo I, Akpa BS. Validity of the lipid sink as a mechanism for the reversal of local anesthetic systemic toxicity: a physiologically based pharmacokinetic model study. Anesthesiology. 2013 Jun;118(6):1350-61.

34. Robin A, Nordenström J, Askanazi J, Elwyn D, Carpentier Y, Kinney J. Plasma clearance of fat emulsion in trauma and sepsis: Use of a three-stage lipid clearance test. JPEN-Parenter Enter. 1980;4(5):505-10.

35. Li J, Fettiplace MR, Chen S-J, Steinhorn B, Shao Z, Zhu X, et al. Lipid Emulsion Rapidly Restores Contractility in Stunned Mouse Cardiomyocytes: A Comparison With Therapeutic Hypothermia. Crit Care Med. 2014 Dec;42(12):e734-40. 
36. Agarwala R, Ahmed SZ, Wiegand TJ. Prolonged use of intravenous lipid emulsion in a severe tricyclic antidepressant overdose. J Med Toxicol. 2014 Jun;10(2):2104.

37. Bologa C, Lionte C, Coman A, Sorodoc L. Lipid emulsion therapy in cardiodepressive syndrome after diltiazem overdose--case report. Am J Emerg Med. Elsevier Inc.; 2013 Jul;31(7):1154.e3-4.

38. Stellpflug SJ, Fritzlar SJ, Cole JB, Engebretsen KM, Holger JS. Cardiotoxic overdose treated with intravenous fat emulsion and high-dose insulin in the setting of hypertrophic cardiomyopathy. J Med Toxicol. 2011 Jun;7(2):151-3.

39. Montiel V, Gougnard T, Hantson P. Diltiazem poisoning treated with hyperinsulinemic euglycemia therapy and intravenous lipid emulsion. Eur J Emerg Med. 2011 Apr;18(2):121-3.

40. Mazoit J-X, Le Guen R, Beloeil H, Benhamou D. Binding of long-lasting local anesthetics to lipid emulsions. Anesthesiology. 2009 Feb;110(2):380-6.

41. Kazory A, Clapp WL, Ejaz a A, Ross E a. Shortened hemofilter survival time due to lipid infusion in continuous renal replacement therapy. Nephron Clin Pr. 2008 Jan;108(1):c5-9.

42. Jeong J. Continuous renal replacement therapy circuit failure after antidote administration. Clin Toxicol. 2014;52(10):1296-7.

43. Monteiro N, Silvestre J. Severe Diltiazem Poisoning Treated with Hyperinsulinaemia-Euglycaemia and Lipid Emulsion. Case Rep Crit Care. 2013;2013:1-4.

44. Assink $\mathrm{M}$, Spronk $\mathrm{P}, \mathrm{Kan} \mathrm{H}$ van, Braber $\mathrm{A}$. Intravenous lipid emulsion in the treatment of verapamil intoxication. Neth J Crit Care. 2013;17(3):18-21. 


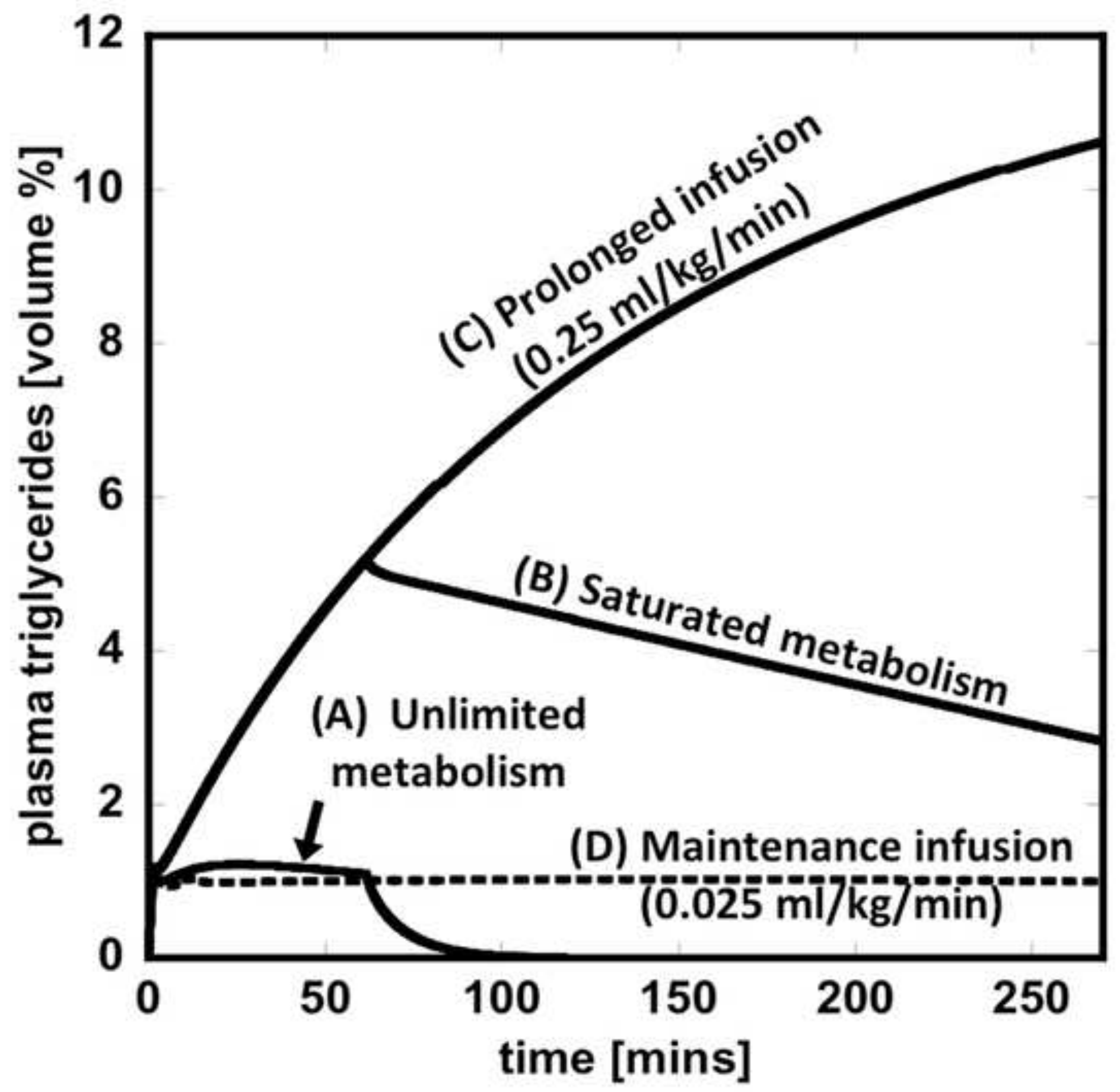

